\title{
Low Temperature Bonding of Alumina/Alumina and Alumina/Copper in Air Using Sn3.5Ag4Ti(Ce,Ga) Filler
}

\author{
S.Y. CHANG, ${ }^{1,3}$ T.H. CHUANG, ${ }^{2}$ and C.L. YANG ${ }^{1}$ \\ 1.-Department of Mechanical Engineering, National Yunlin University of Science \& Technology, \\ Touliu 640, Taiwan. 2.-Department of Materials Science and Engineering, National Taiwan \\ University, Taipei 106, Taiwan. 3.-e-mail: changsy@yuntech.edu.tw
}

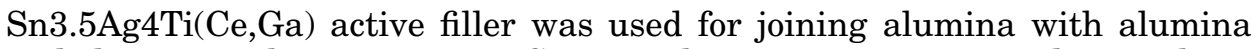
and alumina with copper at $250^{\circ} \mathrm{C}$ in air. The joining process was done without flux and without the need for pre-metallization of alumina or a protective atmosphere. After mechanical activation of the bonding surfaces of alumina and copper, the filler showed good wetting on both alumina and copper and led to a strong bond between alumina and copper. Through tensile testing, a bonding strength of 23.7 MPa was found in the alumina/copper joint region. The shear strengths for alumina/alumina, copper/copper and alumina/copper joints were $13.5,14.3$, and $10.2 \mathrm{MPa}$, respectively. The affinity of cerium for oxygen protects titanium from oxidation, giving rise to the reaction of titanium with alumina at such a low temperature. Electron probe microanalyzer (EPMA) elemental mapping revealed that titanium segregates effectively at the alumina/solder interfaces. After aging tests at $200^{\circ} \mathrm{C}$ and $150^{\circ} \mathrm{C}$, a double layer of $\mathrm{Cu}_{3} \mathrm{Sn}$ and $\mathrm{Cu}_{6} \mathrm{Sn}_{5}$ intermetallic compound was formed at the solder/ copper interfaces. With an increase of aging periods, the amount of brittle compound in the joints increased and resulted in decreases in the shear strengths of the alumina/copper joints.

Key words: Active soldering, alumina, copper, $\operatorname{Sn} 3.5 \mathrm{Ag} 4 \mathrm{Ti}(\mathrm{Ce}, \mathrm{Ga})$

\section{INTRODUCTION}

Copper bonded to alumina substrate has been proven an excellent solution for electrical isolation and thermal management of high quality semiconductor power devices. ${ }^{1}$ Hence, copper-alumina bonding is becoming an important technique and has found wide application in high-performance microelectronic packaging. Owing to environmental concerns, the use of Pb-containing solders will be prohibited or reduced. Among the many $\mathrm{Pb}$-free solders, Sn3.5Ag has been regarded as a promising candidate due to the merits of high strength, longer thermal fatigue life, good creep resistance and low cost. ${ }^{2}$ Although binary Sn3.5Ag alloy shows a satisfactory wettability and solderability with many metallic substrates, it cannot be used for the bonding of ceramic materials without pre-metallization. In the conventional joining of ceramics, the nickel-

(Received September 22, 2006; accepted January 4, 2007; published online July 20, 2007) plated ceramic is brazed after it has been metallized by the molybdenum-manganese method. The active brazing method of ceramic joints is simpler than the molybdenum-manganese methods. ${ }^{3-5}$ The molybdenum-manganese process metallizes the ceramic surfaces by coating it with a mixture of molybdenum and manganese powder, followed by a sintering treatment at high temperature. It has been shown that the addition of active elements in filler metals can effectively improve their wettability on the surface of a ceramic by reducing the liquid/solid surface free energy and formation of the subsequent chemical reactions at the solder/ceramic interfaces. ${ }^{6,7}$ A commercialized $\mathrm{Sn} 10 \mathrm{Ag} 4 \mathrm{Ti}$ solder was developed for this purpose. ${ }^{8}$ With this active solder, sound joints have been obtained for $\mathrm{Al}_{2} \mathrm{O}_{3}, \mathrm{SiC}$ and $\mathrm{ZrO}_{2}$ ceramics. ${ }^{9,10}$ However, the required bonding temperature was up to $900^{\circ} \mathrm{C}$ in spite of the low melting point of $\mathrm{Sn} 10 \mathrm{Ag} 4 \mathrm{Ti}\left(221-300^{\circ} \mathrm{C}\right)$. Also, the bonding process must be conducted in an argon or vacuum atmosphere to prevent the oxidation of the active solder. ${ }^{11}$ Recently, a trace amount of rareearth elements (Ce or La) has been added, along 
with the active element $\mathrm{Ti}$, into the $\mathrm{Sn} 3.5 \mathrm{Ag}$ solder, and the resulting solder can successfully join nonwetting materials at low temperature in air. It has been reported that the addition of rare-earth elements to the active solder can remove oxides at the reaction interfaces of the work pieces during joining, thus eliminating the need for the protective atmosphere otherwise required for the soldering process. ${ }^{11,12}$ In this work, the interfacial reactions and the resultant solderability of alumina/alumina and alumina/copper joints are investigated. The effect of thermal aging duration on joint reliability was studied by measurement of the joint shear strength.

\section{EXPERIMENTAL}

The active solder $\mathrm{Sn} 3.5 \mathrm{Ag} 4 \mathrm{Ti}(\mathrm{Ce}, \mathrm{Ga})$ used in this study was supplied by Euromat Co., Heinsberg, Germany, with a chemical composition (wt.\%) of Sn3.55Ag4.07Ti0.12Ce0.14Ga as analyzed. The ultimate tensile stress of the solder at room temperature was determined at a strain rate of $10^{-3} \mathrm{~s}^{-1}$. Figure 1 shows the dimensions of the tensile test specimens. The melting range (liquidus and solidus) of the active filler $\mathrm{Sn} 3.5 \mathrm{Ag} 4 \mathrm{Ti}(\mathrm{Ce}, \mathrm{Ga})$ was between $218^{\circ} \mathrm{C}$ and $229^{\circ} \mathrm{C}$, as determined with differential scanning calorimetry (DSC) at a heating rate of $10^{\circ} \mathrm{C} / \mathrm{min}$ under an argon atmosphere in a prior study. ${ }^{13}$ The bulk alumina ceramic was fabricated by pressure casting and sintered at $1,600^{\circ} \mathrm{C}$ for $2 \mathrm{~h}$ after $24 \mathrm{~h}$ drying at $60^{\circ} \mathrm{C}$. The metal for joining used in this study was commercial pure copper. The

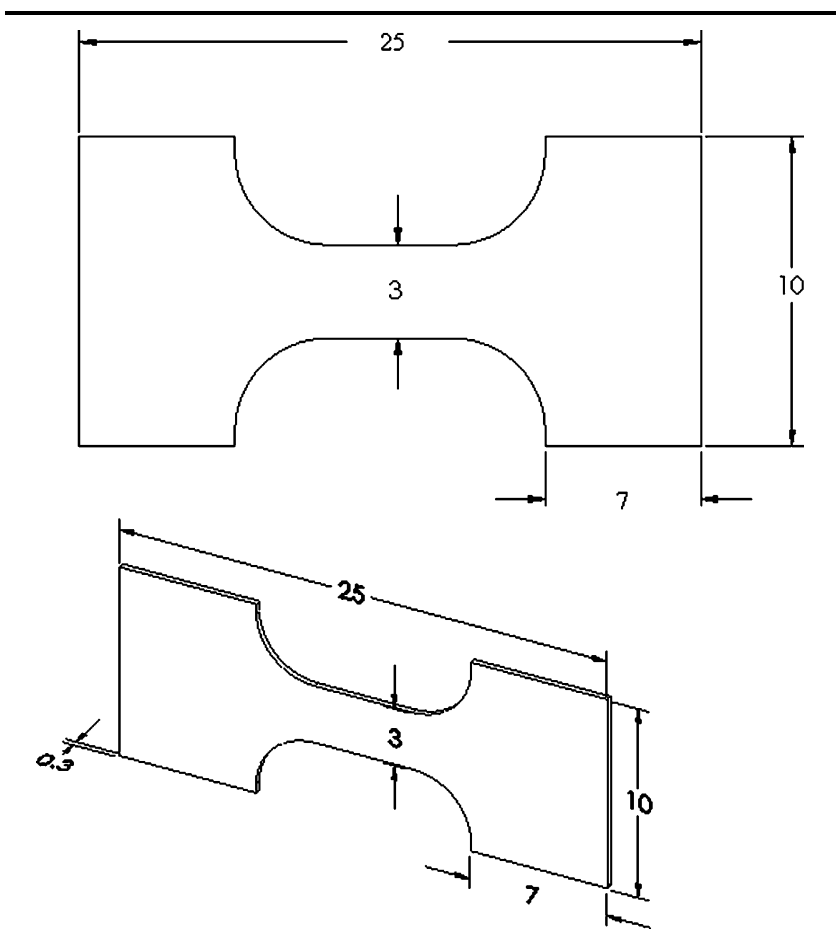

Fig. 1. Schematic representation of the geometry of tensile specimens. geometry and dimensions of the two types of the soldered specimens subjected to tensile and shear testing are demonstrated in Figs. $2 \mathrm{a}$ and $3 \mathrm{a}$, respectively. The bond surfaces of the specimens were wet ground with $\mathrm{SiC}$ paper down to grade 1200 . Prior to soldering, the alumina specimens were preheated on a heating plate at $250^{\circ} \mathrm{C}$ for 5 min. The active solder was then placed on the bond surfaces. The molten solder was agitated for $30 \mathrm{~s}$ for wetting on the bond surfaces, and then a copper or alumina specimen was placed on the molten solder to be joined with an alumina specimen by being rubbed together for $30 \mathrm{~s}$. The joints were held firmly in place and cooled, leading to the solidification of the molten solder. The bonding strengths were measured via tensile and shear testing, as shown in Figs. $2 \mathrm{~b}$ and $3 \mathrm{~b}$, respectively. The effect of thermal aging on joint reliability was studied at $150^{\circ} \mathrm{C}$ for different periods. After aging tests, the bonding strengths were measured by shear testing. Fractured surfaces were characterized using scanning electron microscopy (SEM) coupled to energy dispersion X-ray (EDX). A set of bonded specimens was cut into cross-sections. The microstructures were analyzed by an electron probe microanalyzer (EPMA) to ascertain the bonding mechanism and related interfacial reactions.

\section{RESULTS AND DISCUSSION}

The microstructure of the $\mathrm{Sn} 3.5 \mathrm{Ag} 4 \mathrm{Ti}(\mathrm{Ce}, \mathrm{Ga})$ solder observed by SEM is shown in Fig. 4. A large number of coarse clusters is seen embedded in the solder matrix. These particles reveal a two-phase structure. The chemical composition of the phase in the middle of the coarse clusters (black) was identified by EPMA as Ti:Sn = 54.4:44.5 (at.\%), which corresponds to the $\mathrm{Ti}_{6} \mathrm{Sn}_{5}$ phase. The EPMA analyses indicated that the surrounding phase (gray) in $\mathrm{Ti}: \mathrm{Sn}=38.40: 61.6$ (at.\%), which corresponds to the $\mathrm{Ti}_{2} \mathrm{Sn}_{3}$ phase. The solder had both large plate-type and small particle type $\mathrm{Ag}_{3} \mathrm{Sn}$, as shown in Fig. 4 (seen in white). After two tensile tests, the Sn3.5Ag4Ti(Ce, Ga) solder was found to have an average ultimate tensile stress of 57.3 MPa.

The scanning electron microscopy micrograph of the bonding interfaces of alumina/alumina and alumina/copper joints using the $\mathrm{Sn} 3.5 \mathrm{Ag} 4 \mathrm{Ti}(\mathrm{Ce}, \mathrm{Ga})$ solder at $250^{\circ} \mathrm{C}$ is shown in Fig. 5. That demonstrates a good wettability of the filler metal on the alumina as well as on the copper. It is somewhat difficult to identify the reaction phases of the interface between alumina and solder using only SEM and EDX. EPMA elemental mapping of the alumina/alumina joint (Fig. 6), bonded with $\mathrm{Sn} 3.5 \mathrm{Ag} 4 \mathrm{Ti}(\mathrm{Ce}, \mathrm{Ga})$ active solder, indicates the segregation of $\mathrm{Ti}$ at the alumina/solder interface, as shown in Fig. 6b. Similar enrichment was also observed in prior studies of indium tin oxide (ITO) joints. ${ }^{13,14}$ The trace amount of cerium segregates slightly at the interface (Fig. 6c). Owing to the high 

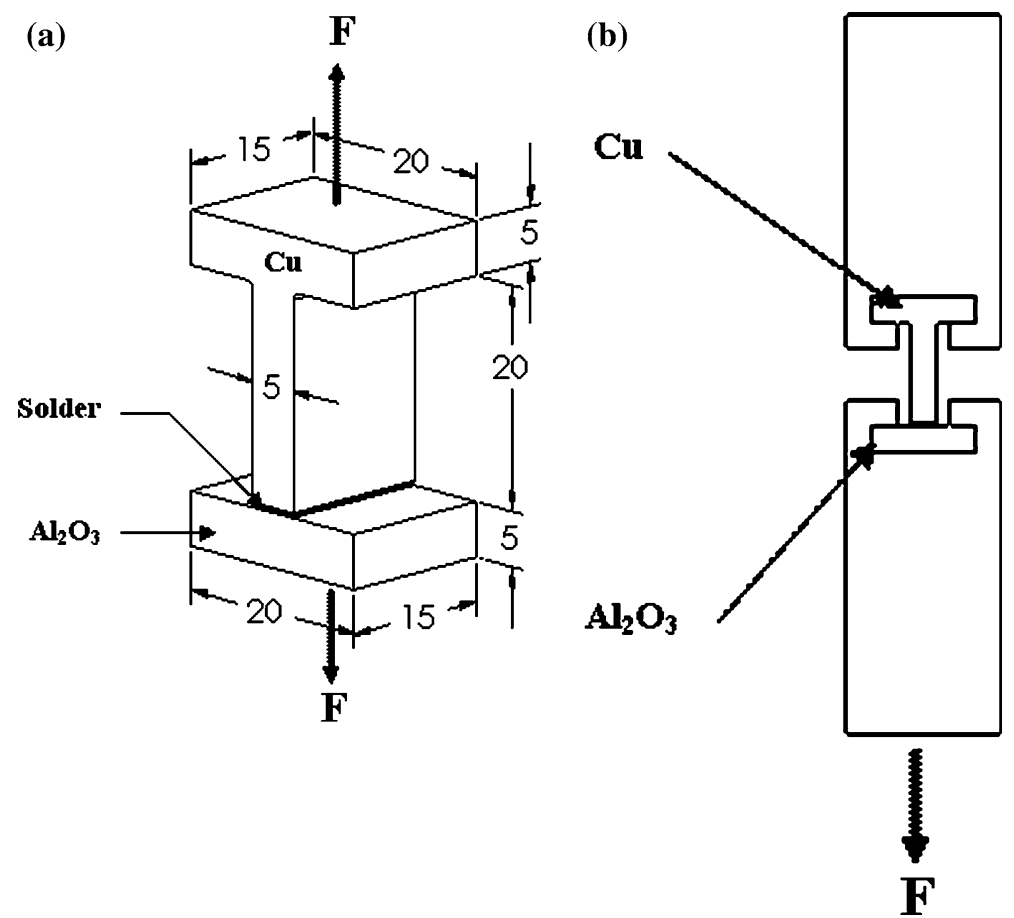

Fig. 2. Schematic representation of the soldered specimens ready for tensile testing in this study.

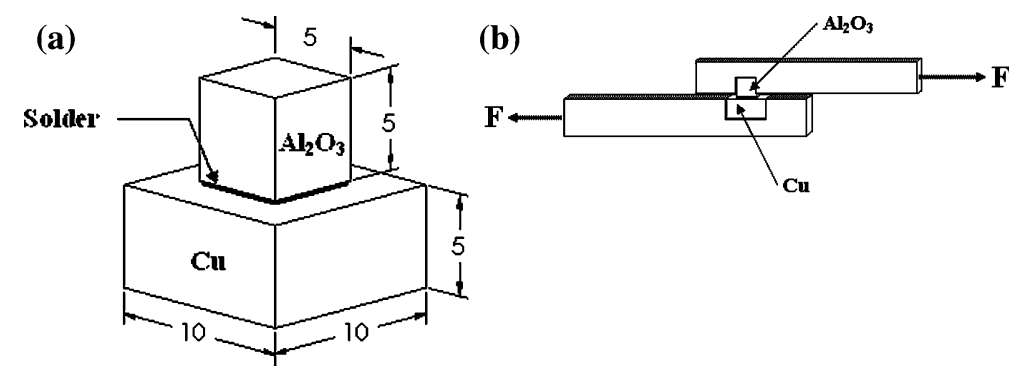

Fig. 3. Schematic representation of the soldered specimens ready for shear testing in this study.

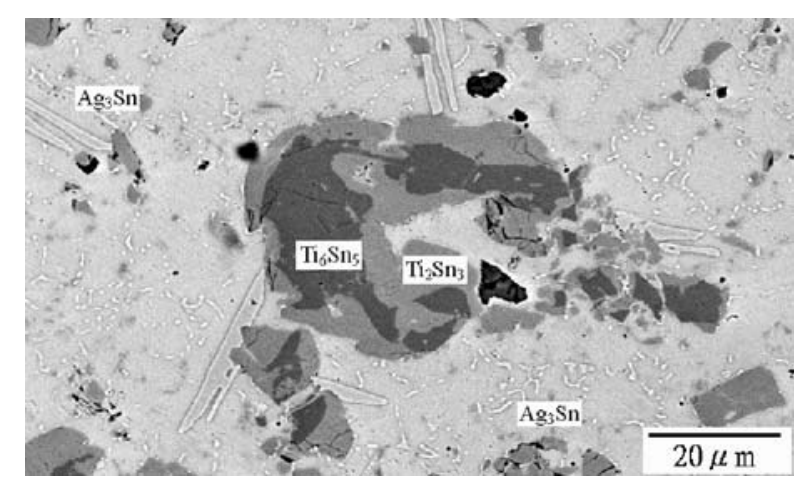

Fig. 4. Microstructure of the Sn3.5Ag4Ti(Ce,Ga) active solder filler.

affinity of cerium for oxygen, the cerium diffuses to the alumina and reacts with it. Moreover, cerium in the solder can protect titanium from oxidation. Thus, the activity of titanium was enhanced, thus promoting the reaction of titanium with alumina.
Figure 7 shows that copper dissolves irregularly to form a scallop-shaped intermetallic compound at the solder/copper interface of the alumina/copper joints. The EPMA analyses indicated that the composition of these scallop-shaped intermetallics was $\mathrm{Cu}: \mathrm{Sn}=53.6: 46.4$, which corresponds to the $\eta$ - $\mathrm{Cu}_{6} \mathrm{Sn}_{5}$ phase. Through tensile testing, a higher bonding strength of $23.7 \mathrm{MPa}$ was found in the alumina/copper joints region. Figure 8 indicates that the fractured surface of the copper specimen was covered with some alumina particles. It is obvious that the alumina/copper joint fractured at the alumina/solder interface.

The shear strengths of alumina/alumina, copper/ copper, and alumina/copper joints using the Sn3.5Ag4Ti(Ce,Ga) solder are given in Fig. 9. The alumina/copper joint possessed a shear strength of 10.2 $\mathrm{MPa}$, which is considerably lower than those for the copper/copper and alumina/alumina joints of similar materials. The thermal expansion coefficients 

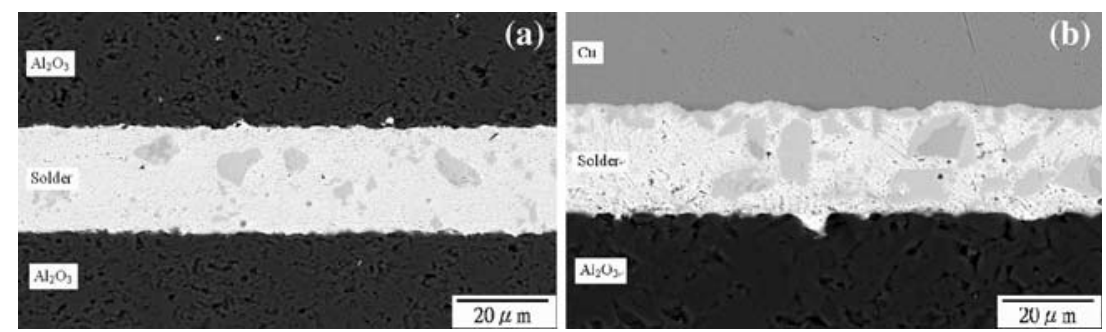

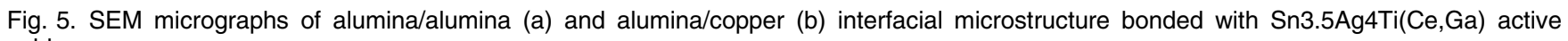
solder.
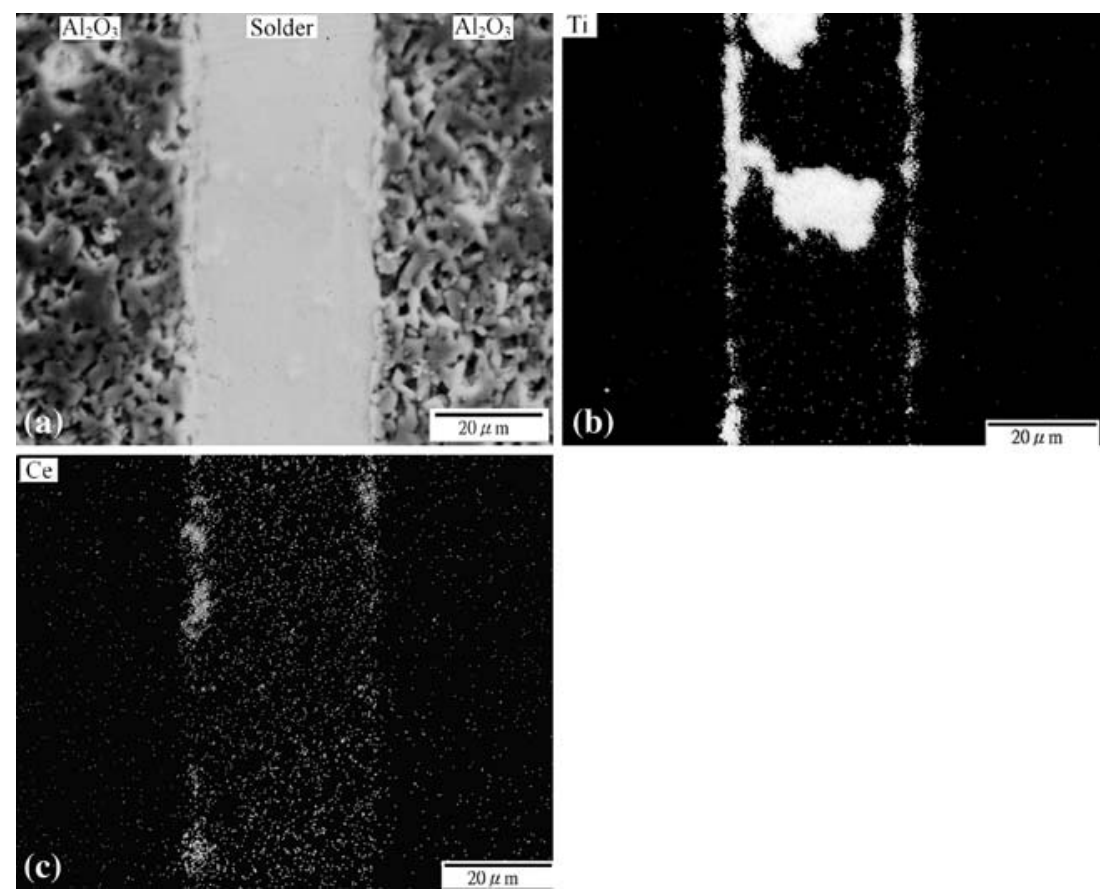

Fig. 6. Micrograph and EPMA analyses of the alumina/alumina joint bonded with Sn3.5Ag4Ti(Ce,Ga) active solder. (a) The interfacial microstructure; (b) and (c) elemental mappings of $\mathrm{Ti}$ and $\mathrm{Ce}$, respectively.

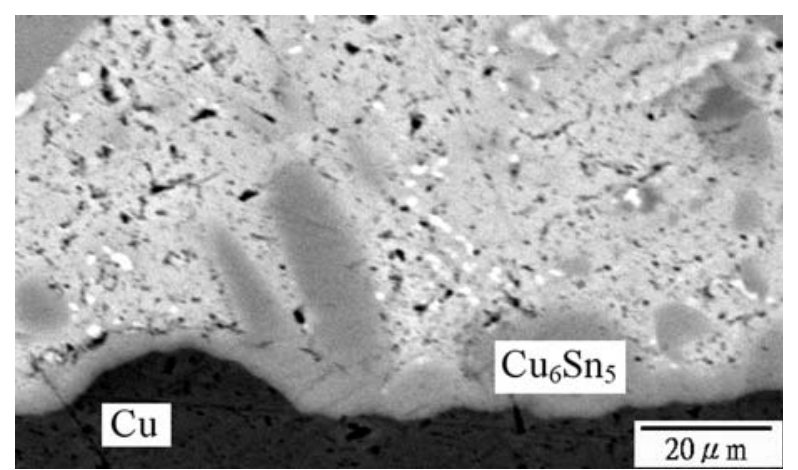

Fig. 7. SEM micrographs of copper/solder interfacial microstructure.

are about $5 \times 10^{-6}, 17 \times 10^{-6}$ and $19 \times 10^{-6} 1 /{ }^{\circ} \mathrm{C}$ for alumina, copper and $\mathrm{Sn} 3.5 \mathrm{Ag} 4 \mathrm{Ti}(\mathrm{Ce}, \mathrm{Ga})$ solder, respectively. ${ }^{15,16}$ The residual stresses generated from the thermal mismatch for the alumina/alumina or alumina/copper joints were larger than those for the copper/copper joint. Hence, the lower shear strength of alumina to alumina as well as alumina to copper joints could be attributed to the residual stress caused by the large thermal expansion mismatch between solder and alumina. Fractography of the specimens after shear tests revealed that the soldered copper/copper joint fractured along the $\mathrm{Cu}_{6} \mathrm{Sn}_{5}$ intermetallic layer.

Figure 10 shows the back-scattered electron images of the interface of the alumina/copper joints after thermal aging testing at $200^{\circ} \mathrm{C}$ for $24 \mathrm{~h}$. A double layer of intermetallic compounds was found at the solder/copper interfaces. The EPMA analyses indicated that the composition of the out layer was $\mathrm{Cu}: \mathrm{Sn}=54.8: 45.2$, corresponding to an intermetallic compound $\mathrm{Cu}_{6} \mathrm{Sn}_{5}$ phase. The internal layer achieved a composition of $\mathrm{Cu}: \mathrm{Sn}=74.6: 25.4$, which corresponded to a $\mathrm{Cu}_{3} \mathrm{Sn}$ phase. The thickness of the intermetallic compounds increased as aging time increased. The shear strengths of alumina/copper 


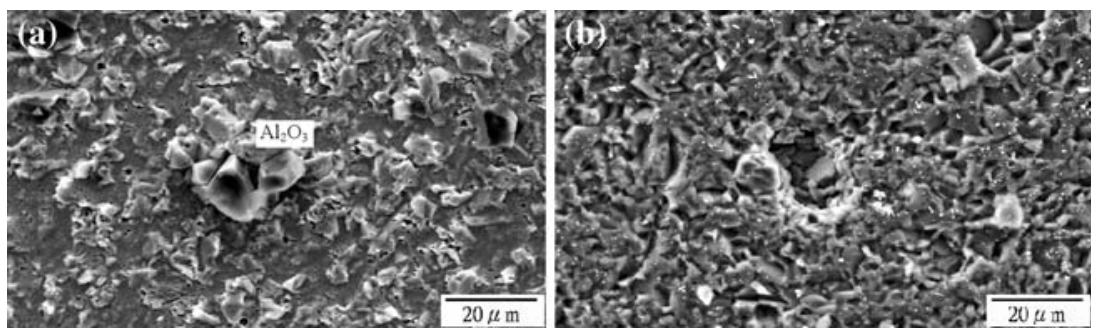

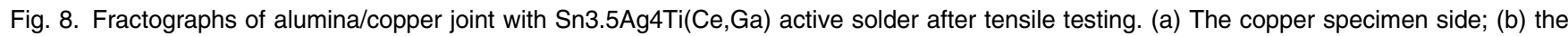
alumina specimen side.

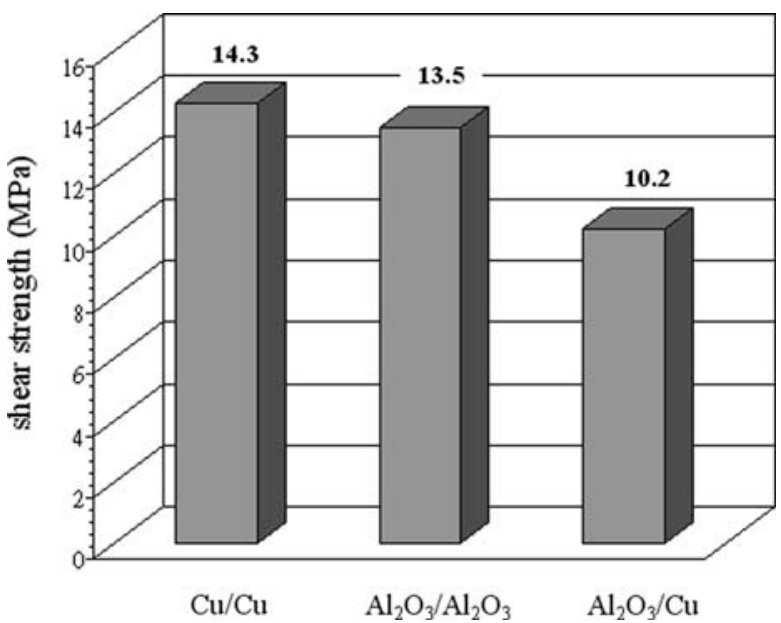

Fig. 9. Shear strengths of copper/copper, alumina/alumina and alumina/copper joints bonded with $\mathrm{Sn} 3.5 \mathrm{Ag} 4 \mathrm{Ti}(\mathrm{Ce}, \mathrm{Ga})$ active solder.

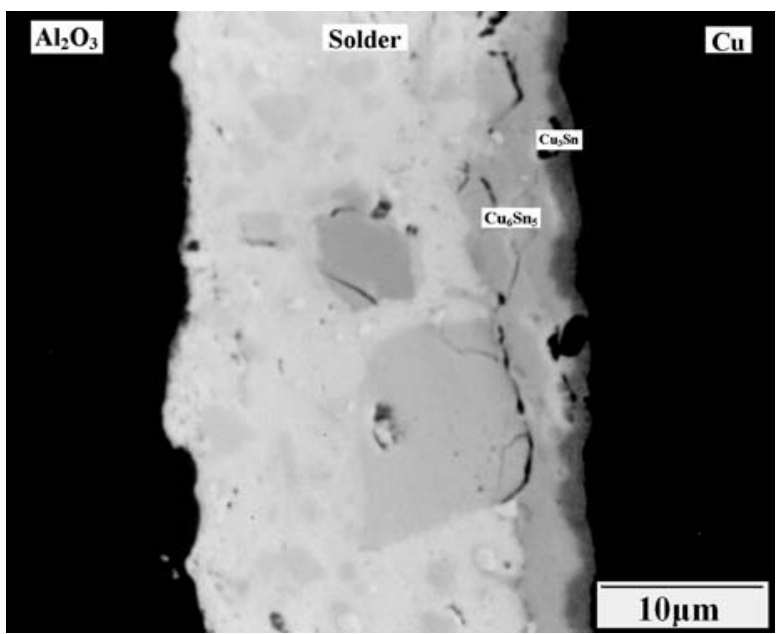

Fig. 10. Micrographs of alumina/copper interfacial microstructure after aging test at $200^{\circ} \mathrm{C}$ for $24 \mathrm{~h}$.

joints after aging testing at $150^{\circ} \mathrm{C}$ are shown in Fig. 11. The results indicate that joint strength decreased as aging time increased. The crosssectional SEM micrograph of the alumina/copper joints after aging testing at $150^{\circ} \mathrm{C}$ for $100 \mathrm{~h}$ is given in Fig. 12. The micrograph clearly indicates that the

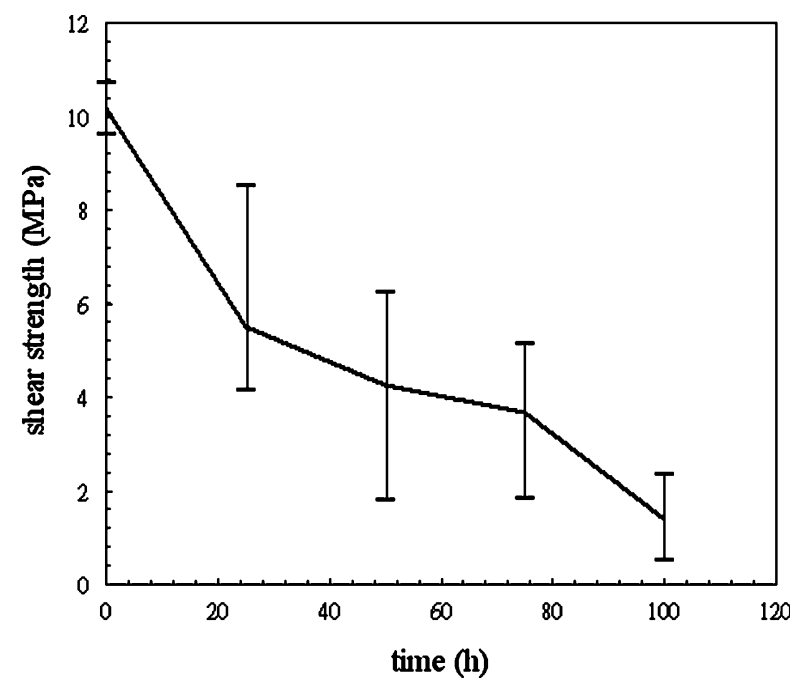

Fig. 11. Shear strengths of alumina/copper joints bonded with Sn3.5Ag4Ti(Ce,Ga) active solder after aging testing.

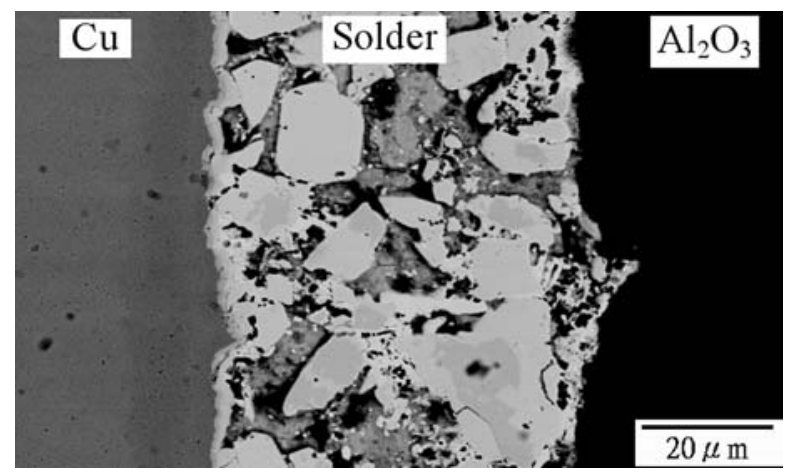

Fig. 12. Micrograph of the alumina/copper joint bonded with Sn3.5Ag4Ti(Ce, Ga) active solder after aging test at $150^{\circ} \mathrm{C}$ for $100 \mathrm{~h}$.

solder is consumed and that quantities of intermetallic compounds are formed. It is argued that the presence of the brittle intermetallic compound resulted in the decrease in shear strength.

\section{CONCLUSION}

A fluxless low temperature bonding technique was developed to join alumina/alumina and 
alumina/copper. The high affinity of cerium for oxygen caused the reaction of cerium with oxygen in solder and alumina. The cerium in the solder is believed to lower the energy of interfacial reaction that promotes the reaction of active element $\mathrm{Ti}$ with alumina at a low bonding temperature $\left(250^{\circ} \mathrm{C}\right)$. Hence, EPMA elemental mapping revealed a strong tendency of $\mathrm{Ti}$ and a slight disposition of cerium to segregate at the alumina/solder interface. During soldering, copper was found to dissolve into Sn3.5Ag4Ti(Ce,Ga) solder to form scallop-shaped $\mathrm{Cu}_{6} \mathrm{Sn}_{5}$ intermetallic compounds. For the active solder, its Sn content tended to react with copper to form a double layer of intermetallic compounds of $\mathrm{Cu}_{6} \mathrm{Sn}_{5}$ and $\mathrm{Cu}_{3} \mathrm{Sn}$ during aging testing. The bonding strengths of copper/copper, alumina/alumina and alumina/copper joints as measured by shear testing were $14.3,13.5$, and $10.2 \mathrm{MPa}$, respectively. The lower shear strength of the alumina to copper joint could be attributed to the residual stress caused by the large thermal expansion mismatch. Aging tests at $150^{\circ} \mathrm{C}$ caused the formation of quantities of brittle intermetallic compounds $\left(\mathrm{Cu}_{6} \mathrm{Sn}_{5}\right.$ and $\left.\mathrm{Cu}_{3} \mathrm{Sn}\right)$ and reduced the bonding strengths of the alumina/copper joints.

\section{ACKNOWLEDGEMENT}

Special thanks go to National Science Council (under Grant \# NSC94-2216-E-224-003) for sponsorship of this research project.

\section{REFERENCES}

1. Y. Yoshino and T. Shibata, J. Am. Ceram. Soc. 75(10), 2756 (1992).

2. J. Glazer, Int. Mater. Rev. 40, 65 (1995).

3. H. Pulfrich, U.S. Patent 2,163,407 (1939).

4. H.J. Nolte, U.S. Patent 2,667,432 (1954).

5. A.J. Chick and L.J. Speck, U.S. Patent. 2,708,787 (1955).

6. A.J. Moorhead, Adv. Ceram. Mater. 2(2), 159 (1987).

7. H. Mizuhara and K. Mally, Weld. J. 64(10), 27 (1985).

8. W. Weise, W. Malikowski, and W. Bohm, Verbinden von Keramik mit Keramic oder Metall durch Aktivloten under Argon oder Vakuum, Firmenschrift Degussa Hanau AG., Hanau, Germany.

9. Y.H. Chai, W.P. Weng, and T.H. Chuang, Ceram. Int. 24, 273 (1998).

10. T.H. Chuang, M.S. Yeh, and Y.H. Chai, Metall. Mat. Trans. 31A, 1591 (2000).

11. F. Hillen, D. Pickart-Castillo, I.J. Rass, and E. Lugscheider, Weld. Cutting 52(8), E162 (2000).

12. R.W. Smith, Weld. J. 10, 30 (2001).

13. S.Y. Chang, L.C. Tsao, M.J. Chiang, C.N. Tung, G.H. Pan, and T.H. Chuang, J. Mater. Eng. Perform. 12(4), 383 (2003).

14. S.Y. Chang, M.H. Lu, L.C. Tsao, and T.H. Chuang, Weld. J. 4, 81 (2006).

15. M. Halvarsson, V. Langer, and S. Vuorinen, Surf. Coat. Technol. 76-77, 358 (1995)

16. S-Bond Technologies, LLC, Bulletin No. 14.01.05, http:// www.s-bond.com (2002). 